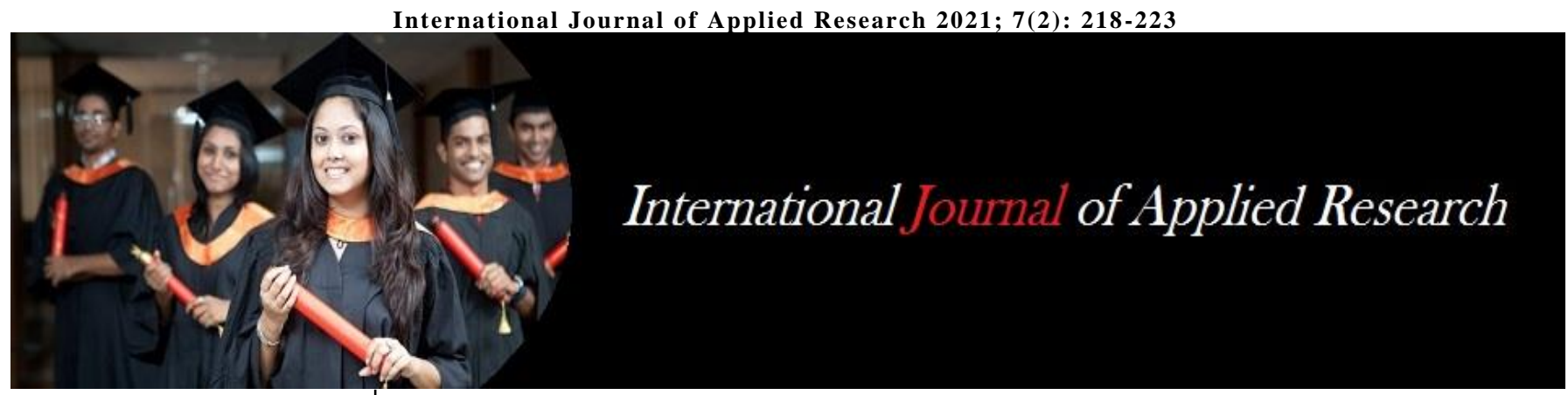

ISSN Print: 2394-7500 ISSN Online: 2394-5869 Impact Factor: 8.4 IJAR 2021; 7(2): 218-223 www.allresearchjournal.com

Received: 13-12-2020 Accepted: 15-01-2021

Karen Celebrado Quackenbush Teacher, Maryland State Department of Education, Baltimore, Maryland

United States of America

Don Alan Quackenbush Virginia Polytechnic Institute and State University, Blacksburg, Virginia, Unites States of America
Corresponding Author: Karen Celebrado Quackenbush Teacher, Maryland State Department of Education, Baltimore, Maryland United States of America

\section{Stylistics analysis of "The charge of the light brigade" by Alfred lord Tennyson}

\section{Karen Celebrado Quackenbush and Don Alan Quackenbush}

DOI: https://doi.org/10.22271/allresearch.2021.v7.i2d.8275

\section{Abstract}

Stylistics relative to interpreting literature shows how an author created the literary piece. It identifies the ways a writer chooses the language in weaving the text. Further, it works on the premise that without language, there can be no literature.

The stylistics analysis of "The Charge of the Light Brigade" provided a deeper understanding of the specific messages of the poem and broader knowledge of the language in general. It identified the usage patterns used by Alfred Lord Tennyson in writing the poem which resulted to a more competent appreciation of the literary work. The analysis revealed how cleverly he weaved each line on the poem that changing the arrangement would ruin the beauty of the poem.

Keywords: brigade, war, punctuation, semantics, imagery, artillery

\section{Introduction}

War stories are never really about wars. They are narratives of horror and honor, grief and relief, misery and bravery. Writers communicate these stories in various written forms with the expectations that people and events are not forgotten and lessons are learned from the past. War stories are not just about history, they are remembrance.

A lot of these stories are the retelling of the horrors and tragedy of war. Some are tales of hopelessness, failure, of soldiers' lives wasted and of sublime heroism. Such is the story behind the poem written by Alfred Lord Tennyson "The Charge of the Light Brigade". Tennyson immortalized the valor and sacrifice of the British Light Cavalry who valiantly carried out their orders knowing they were outmatched by their enemies, the Russians, in the 1854 Battle of Balaclava during the Crimean War.

This poetry of Tennyson evokes feelings of high regard to the soldiers of the Light Brigade who were aware that following orders could cost them their lives. They were surrounded by thundering cannons and yet they unflinchingly fought, thus suffering great casualties.

The famous quote of Dr. A.P.J. Abdul Kalam states that "Poetry comes from the highest happiness or deepest sorrow". This is true in this Tennyson poem where the poet eloquently expressed his praise for the obedience of soldiers and mourned the futility of the charge. Although joy and sorrow are from both ends of the spectrum, these intense emotions summon poetry and are captured beautifully in words and structure.

\section{Poetry}

The dictionary definition of poetry is "writing that formulates a concentrated imaginative awareness of experience in language chosen and arranged to create a specific emotional response through meaning, sound and rhythm" (Nemerove, 2020) [13]. Poetry has its beginnings thousands of years ago and were handed from generations to generations through oral traditions. Poetry is the expression of human cognition and emotion and is written by line, the basic structure of poem. This appearance gives cue on the ways poetry is delivered orally. So much different from the usual voice and pitch because poetry according to Ben Johnson "speaketh somewhat above the mortal mouth.". In poetry, complex messages are concealed in simple words, The choice of concrete words that are notably effective and remarkably sensitive, result to clarity of abstract emotions. 
In the Charge of the Light Brigade, Alfred Lord Tennyson, clearly described the savagery of war and the cavalry of men riding to their deaths for ends they did not question. He used words that are simple yet so powerfully woven, they evoked an emotional response because the reader can vividly imagine the futility of the charge. In the second stanza, the line "Was there a man dismayed" is actually asking if there was anybody that was intimidated because of the formidable odds against them. The subsequent lines "Theirs not to make reply, Theirs not to reason why, Theirs but to do and die" describe how the cavalry fearlessly rode amidst the thundering cannons to follow their orders even if it meant death.

The poem "The Charge of the Light Brigade" is a narrative and a tribute to the British soldiers who did not question the wrongful order but chose to stand against an enemy with far superior forces. It is a compelling storytelling of the Battle of Balaclava in poetic form.

\section{Stylistics Analysis}

Language is the medium that delivers thoughts and emotions from one entity to another and this is the reason writers write. The effective use of language include " all the devices of language that are used to achieve communication in speech and in writing" (Alo, 1998, p. 1) $)^{[1]}$.

Stylistics analysis is the deep examination and thorough interpretation of a literary piece in written form and aims to unfold the simplicity and complexity of the words used that enhance the messages and generate reaction from readers. Stylistics is analyzing the terms and devices used in creating a literary piece that is both artistic and scientific. Widdowson (1975) ${ }^{[21]}$ defines stylistics as the ways while language is the subject. Leech (1969) ${ }^{[11]}$ concluded that stylistics is the clarification of the relationship between the aesthetics function and linguistics.

\section{Features of Stylistics Analysis}

Examining the words used in poetry is important because it can lead to the efficient analysis of the poem thus leading to effective interpretation and achieving accurate meanings. This kind of resource in poetry is the demonstration of the special ways words are chosen to compose the poem and in turn produces specific effects that are accurate and meaningful.

\section{Graphology}

Punctuation in poetry according to Samson (2015) ${ }^{[16]}$ serves the same purpose in prose and bar lines in music. Punctuation and bar lines are the means for words to have flow of thoughts and music to have melody of sounds. Various punctuations can make a series of random words meaningful.. These marks suggest the perception of the words as they indicate the manner the words sound when orally expressed. Mood and tone of joys, fear, surprise, hesitation, doubt etc. can be conveyed by using appropriate punctuation marks. Proper use of punctuation marks enhance the tone of sentences and provide correct interpretation. Punctuation in poetry is essential in conveying clear and concise meaning.

The verses and lines of Charge of the Light Brigade are replete with punctuation marks. The type of verses are identified by the location of the punctuation they contain and enumerated by Samson (2015) ${ }^{[16]}$ as 1) End-stopped line - a punctuation is placed at the end of the line, purposely to pause 2) Run-on line/Enjambment punctuation is not placed at the end of line and the idea is continued to the next line and finally 3) Caesura punctuation mark is usually placed in the middle of a line. These punctuations are the rhythm's natural pause in speech rather than by meter.

\section{Period}

Every stanza of the poem has a period and 5 out of 6 stanzas end with a period. Periods appear on specific location in the poem to indicate finality to the thought of a line. It provides the reader pause and contemplate on what has been expressed so far and by far.

\section{Comma}

A comma is used to end 18 lines and it is also used in 2 lines to separate ideas. Commas when used properly can lead to make meaning clear by grouping and separating words, phrases and clauses. The punctuation is short pause in writing and short breath in speaking.

\section{Quotation mark}

"Forward, the Light Brigade!

Charge for the guns!" he said.

"Forward, the Light Brigade!"

Quotation marks give life to writing because readers imagine a person speaking. These are two lines in the entire poem with quotation marks representing the exact spoken language and providing an image of a person saying the words. The quotation marks in the lines were indispensable in the poem because they emphasized the direct, clear and accurate speech that designated the act of command.

\section{Exclamation point}

"Forward, the Light Brigade!

"Forward, the Light Brigade!"

$O$ the wild charge they made!

Honour the charge they made!

Noble six hundred!

Exclamation point can turn a declarative sentence into a command, referred to as "note of admiration" and generally placed at the end of a sentence. In the poem, six lines ended with exclamation points to purposely emphasize strong emotions, indicate sudden outburst of passion and express evident excitement.

The two lines "Forward, the Light Brigade! "Forward, the Light Brigade!" are said with the loud command. "O the wild charge they made!" expresses a strong admiration. "Honour the charge they made!" is passionate begging for admiration and "Noble six hundred!", conveys high regard to the soldiers for their heroism and dedication to the duty they are sworn to uphold regardless of the consequences.

\section{Question mark}

Was there a man dismayed?

When can their glory fade?

Question mark ends a sentence to indicate a question or a direct question. Two lines in the poem end with a question mark, grammatically showing interrogative sentences and 
readers of the poem are expected to provide answers or information.

Interrogative sentences are used with the intention of expressing emotional attitude, Hye-Jin Min and Jong C. Park (2007) ${ }^{[8]}$. In this poem, that emotion is anger. According to (Ortony et al., 1988) ${ }^{[14]}$ anger is motivated when a person blames someone or something based on their level of judgement. The question "Was there a man dismayed?" is an indication of anger because the soldiers knew someone made mistake that certainly led to death. The soldiers followed the command anyway because that was their duty and that someone has to be blamed.

The question "When can their glory fade?" can be a rhetorical question, Quackenbush, et al (2019) ${ }^{[15]}$ explain, this may not have answers or the answers are obvious but asked to make a point. The emphatic answer is they will be forever be honored for bravely marching into the Valley of Death.

\section{Lexicology}

Lexicology involves the deep awareness of meaning of words including their connotation and denotation. The analysis of the words used in the poem is significant in the interpretation of the messages and meanings. The carefully chosen words and examining the words used in poetry are important because they lead to efficient analysis of the poem thus leading to effective interpretation and achieving accurate meaning. This kind of resource in poetry is the demonstration of the special ways words are chosen to compose the poem and in turn produces a specific effect that are precise and truthful. The following words in the poem have deeper meanings and suitably used to convey true feelings and thoughts.

Half a league is an indication a part of whole, telling the soldiers that the distance is not that far off a distance. The distance is too short that after performing their duties, the make it alive and hopeful.

Valley of death is taken from Psalm 23, that begins with 'The Lord is my shepherd...'): 'Yea, though I walk through the valley of the shadow of death, I will fear no evil: for thou art with me; thy rod and thy staff they comfort me.'. Men make and follow mistakes and blunders, the words chosen for this poem express the Lord will definitely see the good overcoming evil. Readers can find that such messages are comforting because of the hope it gives to this physical life and that there is heavenly rewards if life is offered for the love of country.

Rode is past tense of the verb ride indicating not an ordinary horse ride but a journey that will lead to certain death. Ride a horse means one cannot just stop anytime but has to control the horse in order for stop to happen. In the poem the soldiers are not in the position to control their fate.

Someone is a well-chosen word in the poem, telling a generic person and rank who is in command, in order to protect officers or rank who may have ordered a wrongful command that led to certain death of soldiers.

Theirs is possessive pronoun referring to someone or something belonging to or connected to. The word was carefully chosen that though the soldiers have the ownership of asking for the sanity of the blunder, in the poem it is not the soldiers' decision, position or question to defy the situation or order. They only possess the decision to unquestionably follow a wrongful order even if it means their certain death.
Jaws of hell personifies hell by exhibiting a human act of swallowing. Consistent with the previous valley of death from the biblical Psalm 23, this line is taken from Jonah 2:6b "But You, O Lord my God, snatched me from the jaws of death". This is in reference to the story of Jonas who was swallowed by a big fish and he described his experience inside the fish as filled with distress and darkness. Similar to the situation of the light brigade.

\section{Semantics}

Semantics is the creation of texts in any form. It is necessary according to Dever (1978) ${ }^{[4]}$ to put together words to state complex ideas or relationships in phrases and sentences. This statement is consistent with Lyons (1977) ${ }^{[12]}$ that "the function of language tends to be reflected in its grammatical and lexical structure, which interrelate sentences with the feature of situation of the utterance" (p.249).

\section{Complex Sentence}

Complex sentences in the poem were used as an effective manner to tell that one idea takes precedence over another because any of the two cannot stand alone. Complex sentences present connections of clauses such as contrast, cause and effect, conditions and time relationships in order to allow readers to focus on the one part of the sentence over the other. Generally, the idea in the independent clause is more significant than the dependent clause.

Each line in every pair of 4 complex sentences in which clauses are used to expand or add information so that readers are assured of the clarity of the message. Each clause is utilized to specifically relate to the each other in order to avoid ambiguity in given information (Franklin, 2016) ${ }^{[7]}$ and to express specific message purposely to signify the attitude of sentiment and sympathy. When an event is emotionally charged to the extreme, packing enormous passion and admiration in one sentence is essential. In this case, the structure of complex sentence is the best option to verbalize the integration of information at its height (Chafe and Danielwicz, 1987) ${ }^{[2]}$

Not though the soldier knew

Someone had blundered.

Stormed at with shot and shell,

While horse and hero fell.

Charging an army, while

All the world wondered.

Then they rode back, but not

Not the six hundred.

\section{Tricolon}

Tricolon is a pattern of three words, phrases or sentences combined to make one powerful impression to readers because it emphasizes a point in a memorable and indelible ways. Humans can easily process information when they recognize patterns and the power of three is a writing principle that any ideas and thoughts expressed in threes are more emphatic, more convincing and more effective than any other numbers. Readers will likely remember the information because having three entities combine both brevity and rhythm with a few words to create a pattern. It is an indication that the writer is knowledgeable while being brief and enduring.

The foregrounding of the poetic language of The Charge of the Light Brigade is through repetition. In the stanza, three 
times the words "half a league" are repeated in succession. The repetition of the phrase to the senses and creates a dactylic rhythm which gives reader the sensation of being on a horse marching onward.

Half a league, half a league,

Half a league onward,

The use of tricolon in 2 stanzas, beginning with the word "cannon" and ending with "them" in every line. This indicates the locations of the cannon, creating clear mental picture of soldiers being surrounded by artillery so enormously powerful that they are riding towards the "valley of death". And throwing themselves "into the jaws of hell", a vision of jaw is waiting to swallow them. They bravely fought with full knowledge that their charge is doomed because "someone had blundered".

Cannon to right of them,

Cannon to left of them,

Cannon in front of them

Cannon to right of them,

Cannon to left of them,

Cannon behind them

The most memorable lines in the poem is tricolon and begin with the possessive pronoun "Theirs". Each line speaks obedience, loyalty and sacrifice for the love of country The repetition of the word Thiers three times articulate the attitude of soldiers to follow authority, the confidence to comply with the order and pride to act on command even it means certain death. The blunder of the commander became the burden of the soldiers. (Gorman, 2021) ${ }^{[6]}$

Theirs not to make reply,

Theirs not to reason why,

Theirs but to do and die.

\section{Repetition}

Repetition, repeats the same words or phrases to emphasize ideas, intensify the thoughts and sustain the memory of the poem. The repeated lines in the poem maintain rhythm and attract attention towards a powerful message. Purposely, repetition is persuasive, notable and entertaining because words are savored, a point is understood and a cause is believed.

The repetition in the poem is anaphora, the successive lines begin with same words or phrases. This device appeals to the feelings of the readers as they are led by the words with a sense of unity and anticipation because they expect what comes next and evoke emotional participation to the theme of the poem. The repetition makes line easy to read and memorize. The anaphora and the rhythm from the dactylic syllables are very appealing. The same word or phrases being repeated, makes the picture of the Light Brigade being surrounded by Russian artillery more vivid engaging the five senses of the reader.

"Forward, the Light Brigade!

Charge for the guns!" he said.

"Forward, the Light Brigade!"

Was there a man dismayed?

The repetition emphasizes the definite destination of the soldiers of being swallowed by "jaws" and "mouth" of death and hell suggesting agonizing and everlasting demise.

Into the jaws of Death,

Into the mouth of hell

Into the valley of Death

Rode the six hundred.

Into the valley of Death

Rode the six hundred.

The anaphora of the words in each line emphasizes the unyielding physical and emotional effort of the light brigade to fight a losing battle. An image of chaotic and harsh movement of a battlefield is revealed, at the same time a picture of devastation as they fight with swords against cannons. Though their fate is doomed from the beginning, they charged and died with bravery and pride.

Flashed all their sabres bare,

Flashed as they turned in air

Volleyed and thundered;

Stormed at with shot and shell,

Volleyed and thundered;

Stormed at with shot and shell,

The repetition of the first word "Honour", articulate the purpose of honoring and remembering the immeasurable courage and loyalty of the light brigade.

Honour the charge they made!

Honour the Light Brigade.

Another type of repetition is epistrophe, words that are repeated at the end of the lines, can be very dramatic. This figurative device contributes to the rhythm and cadence to the speaker's voice and emphasis that effectively attracts attention and evoke a sense of urgency.

These 2 stanza has actually anaphora and epistrophe, the repetition of the same beginning word (Cannon) and the same ending word (them). The repetition of the cannon, creates an auditory image of deafening sound of explosion coming from all directions, where death is certain. The unrelenting fires of cannons is specifically intended for "them" the soldiers. "Them" are disastrously charging the enemy line with a full knowledge that they following an order they are sure to lose. Yet, they proud to do this sublime sacrifice for the name of patriotism.

Cannon to right of them,

Cannon to left of them,

Cannon in front of them

Cannon to right of them,

Cannon to left of them,

Cannon behind them

\section{Phonology}

Written words express meaningful ideas and when spoken, these words have suggestive power in their sound, the stylistic effects are achieved. Yeibo and Stanbic (2014) ${ }^{[5]}$. Phonological features of a poem is 'the expression or realization of language in its spoken form'. Wales (2011, p.318) ${ }^{[19]}$. This means that repertoire of speech sounds and rules for their combination of a language are organized in the mind and used to convey a powerful meaning. Tennyson 
deliberately choose and combine words with phonetic substance, vibration and quality in order transmit meanings that can console or incite the ear Alo (1998) ${ }^{[1]}$ He further creatively use words with inherent sound qualities because they produced special effects and extraordinary messages.

Charge of the Light Brigade is composed of six stanzas numbered with roman numerals. Each stanza is in varying number of lines. Stanza I has 8 lines, Stanza II has 9lines, Stanza III has 9 lines, Stanza IV has 12 lines, Stanza V has 11 lines, Stanza VI has -6 lines. The last two words in all stanzas is "six hundred". Meter is the stressed and unstressed pattern of syllables in poetry. The rhyme scheme of Charge of the Light Brigade is dactyl, each line has a stressed syllable followed by two unstressed syllable. This pattern emphasizes certain words and created rhythm and pause. On the other hand, the inconsistent number of lines every stanza, the obvious lack prescribed of rhyme scheme indicates the chaos, disorder and confusion in the midst of war.

\section{Alliteration}

Alliteration is the repetition of usually a consonant sound at the beginning of a series of word that can potentially adds rhythm to the poem. The purpose of alliteration is to highlight specific words to direct attention in order to make the message important to readers or listener and to make the words retainable to memory. Alliteration is used to evoke mood. Words can be used to describe thoughts and feelings yet some sounds of letters create connotations and its repetition highlight that effect. Further, the repetition of the same consonant sounds puts emphasis and effect on the lines or verses, a helpful tool in memorizing and understanding poetry (Lea, 2008) ${ }^{[10]}$ Alliterations are evidenced in the following words:

do and die, the alliterative sound of $d$ give a sense of abruptness and authority that elicit reaction and produces a revolting and dismal effect on the reader.

Shot and shell, sabre stroke, Shattered and sundered. the alliteration of "s" create a sense of quickness and smoothness sound and imitates the explosive sound of gunshots in the battlefield as described in the poem. The mental picture of overwhelming stormed with shot and shell is clear, a defenseless and desperate situation.

Sibilants are reminders of the snakes, the image of evil. The "s" suggests the malice and slyness of serpent. Further the repeated sound of "s" emphasizes words that resonate with main ideas or themes of the literary composition and can give language a musical element. The repetition of "s" sound tend to catch the attention of reader and hard to ignore. Words that share common sounds in a series results for the words to be memorable. Poems are generally memorized and recited, sibilance aids in this process. (Schlegel, 2017) ${ }^{[17]}$

world wondered, the alliteration sound of " $w$ " creates hushed feeling which is reinforced by the resemblance of the sound to the actual thought awe and to emphasize the part of the poem and to make it easy to remember. The world wonder, is compelling idea of how can the light brigade remain loyal and steadfast to their duty with the knowledge they are headed to their certain death.

horse and hero, the repeated sound of " $h$ " creates breathlessness and comforting effect, thus provide structure and rhythm. The repetition of the sound has visual and auditory function and amplification purpose. Thus, scene and sound of galloping horses with heroes riding charging in the midst of chaotic and terrifying battlefield are amplified.

\section{Conclusion}

Stylistics analysis has proven that it is a comprehensive and descriptive method of understanding and interpreting literature as shown in the analysis of the poem "The Charge of the Light Brigade" by Alfred Lord Tennyson. The analysis had achieved the goals of guiding the readers in comprehending the message precisely and interpreting the poem meaningfully. It weaves from the lexical interpretation of the text to its semantic realm in an organized manner. Examining the poem by investigating the aspects of graphology, semantics, lexicology and phonology is exposing the abstract yet concrete elements of literary composition.

\section{References}

1. Alo M. Style in Language and Communication. PortHarcourt: Aeddy Link 1998.

2. Chafe, Wallace and Danielewiicz, Jane Properties of Written and Spoken Language. In Rosalind Horowitz and S. Samuels (eds). Comprehending Oral and Written Language. San Diego: Academic Press. 1987, 83-113.

3. Chapman R. Linguistics and literature: An introduction to literary stylistics. Littlefield, NY: Adams \& Co. 1973.

4. Dever R. T.A.L.K.: Teaching the American Language to Kids. Columbus: Charles E. Merril 1978.

5. Ebi Yeibo, Akerele Stanbic. Phonological Foregrounding in Chimamanda Adichie's Purple Hibiscus. International Journal of Language and

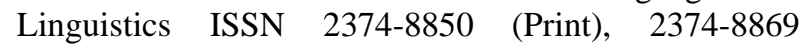
(Online) 2014;1(2).

6. Gorman, Amanda. The Hill We Climb. Delivered during the Inauguration of President Joseph Biden of United States of America on January 20,2021.

7. John Franklin WIREDU., Journal of Literature, Languages and Linguistics www.iiste.org ISSN 24228435 An International Peer-reviewed Journal 2016, 22,

8. Hye-Jin Min, Jong C Park. Analysis of Indirect Uses of Interrogative Sentences Carrying Anger. Computer Science Division EECS Department, KAIST 373-1 Guseong-dong, Yuseong-gu Daejeon 305-701 South Korea \{hjmin, park\}@ nlp.kaist.ac.kr

9. Abdul Kalam PJ. Quotes. (n.d.). BrainyQuote.com. Retrieved February 14, 2021, from BrainyQuote.com Web site: https://www.brainyquote.com/quotes/a_p_j_abdul_kala m_589717

10. Lea R, Brooke Lea. The Power of Peter Piper: How Alliteration Enhances Poetry, Prose, and Memory 2008

11. Leech G. A Linguistic Guide to English Poetry London: Longman 1969.

12. Lyons J. Semantics Cambridge: CUP 1977;1(2).

13. Nemerov H. Poetry. Encyclopedia Britannica 2020, https:// www.britannica.com /art/poetry

14. Ortony A, Clore GL, Collins A. The Cognitive Structure of Emotions. Cambridge University Press 1988.

15. Quackenbush, Karen C, Quackensbush A, Don Epe, Pearl Krizza C, Epe et al. Stylistics Analysis of Sonnet 
18 by William Shakespeare. Int $\mathbf{J}$ Appl Res 2019;5(5):233-237.

16. Samson. Kukogho Iruesiri. Understanding Poetry: The Place of Punctuation in a Poem 2015.

17. Schlegel, Chris. "Sibilance." Lit Charts. Lit Charts LLC, 2017

18. Vineski, Patricia. Caesura in Poetry: Definition \& Examples.) 2015 Retrieved from https://study.com/academy/lesson/caesura-in-poetrydefinition-examples-quiz.html.

19. Wales K. A dictionary of stylistics. Harlow: Pearson Longman 2011

20. Westin, Ingrid. Language Change in English Newspaper Editorials. Amsterdam 2002.

21. Widdowson HG. Stylistics and the Teaching of Literature London: Longman 1975.

22. https://www.linkedin.com/pulse/understanding-poetryplace-punctuation-poem-kukogho-iruesiri-samson/T

23. http://msmitchellsclasses.weebly.com/uploads/4/6/7/4/4 674576/alliteration_chart.pdf 